\title{
Heparin-binding apoproteins
}

\section{Effects on lipoprotein lipase and hepatic uptake of remnants}

\author{
Jayme BORENSZTAJN, ${ }^{*}$ Thomas J. KOTLAR and Charles A. MATZA \\ Department of pathology, Northwestern University Medical School, Chicago, IL 60611, U.S.A.
}

\begin{abstract}
1. Apoprotein-free heparin-binding and non-binding chylomicrons were used as substrates to test the effects on lipoprotein lipase activity of $(a)$ chylomicron protein I; $(b)$ the mixture of proteins I, II and apoprotein $\mathrm{E}$ and $(c)$ human $\beta_{2}$-glycoprotein I. No activation of the enzyme was observed with any of those apoproteins. 2. When rats were injected simultaneously with $\left[{ }^{3} \mathrm{H}\right]$ cholesterol-labelled heparin-binding chylomicrons (containing proteins I and II) and $\left[{ }^{14} \mathrm{C}\right]$ cholesterol-labelled non-binding chylomicrons, no differences were detected between the rates of removal from circulation of those two types of particles. 3. Clearance of chylomicrons from circulation was accompanied by the incorporation of ${ }^{3} \mathrm{H}$ and ${ }^{14} \mathrm{C}$ labels into the livers at similar rates. 4. it is concluded that proteins I, II and apoprotein $\mathrm{E}$ have no effect on the degradation of chylomicrons by lipoprotein lipase and that the hepatic recognition of remnants does not appear to be affected by proteins I and II.
\end{abstract}

\section{INTRODUCTION}

We have recently demonstrated (Borensztajn et al., 1985) that rat lymph chylomicrons can be separated by affinity chromatography on heparin-Sepharose into two distinct fractions: a major fraction that is eluted from the column with the void volume and a similar fraction that binds to the heparin-Sepharose. These two fractions differ in their lipid as well as in their apoprotein compositions. Whereas both fractions contain the wellcharacterized apoproteins B, A-IV, E, A-I and C, the chylomicrons that bind to the column have, in addition, two proteins not found in the unbound fraction. These proteins, which we termed 'proteins I and II', share with apoprotein $\mathrm{E}$ the property of binding to heparin. Protein I appears to be identical with $\beta_{2}$-glycoprotein I. The association of $\beta_{2}$-glycoprotein I with chylomicrons has been previously reported (Polz \& Kostner, 1979; Polz et al., 1980), and the suggestion has been made (Nakaya et al., 1980) that this protein may function in the modulation of the hydrolytic action of lipoprotein lipase on chylomicron triacylglycerols. This suggestion was made on the basis of experiments in which the hydrolysis in vitro of emulsified triacylglycerols by lipoprotein lipase purified from post-heparin plasma was weakly stimulated by high concentrations of $\beta_{2}$-glycoprotein I. This stimulation was more pronounced when apoprotein C-II was present in the assay medium.

In the present study we used chylomicrons to investigate whether the catalytic action of lipoprotein lipase on its physiological substrate is affected by $(a)$ $\beta_{2}$-glycoprotein I from human plasma and $(b)$ protein I Irom rat chylomicrons alone, or in combination with protein II and apoprotein E, the other two heparin-binding proteins of chylomicrons. In addition, we compared the rates of removal from circulation of heparin-binding and non-binding chylomicrons.

\section{MATERIALS AND METHODS}

\section{Preparation of chylomicrons}

The thoracic ducts of male Sprague-Dawley rats (180-220 g) were cannulated by the technique of Bollman et al. (1948) and the animals were then fed by stomach intubation a lipid mixture $(1 \mathrm{ml}$ of corn oil and $3 \mathrm{ml}$ of egg yolk) containing $60-250 \mu \mathrm{Ci}$ of $\left[1,2(\mathrm{n}){ }^{3} \mathrm{H}\right]$ cholesterol (sp. radioactivity $50 \mathrm{Ci} / \mathrm{mol}$ ), $25 \mu \mathrm{Ci}$ of $\left[4-{ }^{14} \mathrm{C}\right]$ cholesterol (sp. radioactivity $55 \mathrm{Ci} / \mathrm{mol}$ ) or $250 \mu \mathrm{Ci}$ of [1-14C]palmitic acid (sp. radioactivity $58 \mathrm{Ci} / \mathrm{mol}$ ) (Amersham, Arlington Heights, IL, U.S.A.). The lymph was collected during the following $12 \mathrm{~h}$ at room temperature in the absence of preservatives. The chylomicrons were then washed and purified of contaminating lymph proteins as previously described (Borensztajn et al., 1985).

\section{Affinity chromatography using heparin-Sepharose}

Separation of chylomicrons into heparin-binding and non-binding fractions was as previously described (Borensztajn et al., 1985), except that a step gradient, rather than a linear gradient was employed. Non-binding chylomicrons were eluted with $70 \mathrm{ml}$ of $2 \mathrm{~mm}$-sodium phosphate, $\mathrm{pH} 7.4$, containing $0.05 \mathrm{M}-\mathrm{NaCl}$. Over $95 \%$ of the particles eluted with this buffer were present in the first $20 \mathrm{ml}$ of eluate. Heparin-binding chylomicrons were then eluted with $40 \mathrm{ml}$ of the same buffer containing $0.5 \mathrm{M}-\mathrm{NaCl}$. Heparin-binding and non-binding apoproteins were separated as previously described (Borensztajn et al., 1985). Non-binding proteins were eluted first with 2 mM-sodium phosphate, $\mathrm{pH} 7.4$, containing $0.05 \mathrm{M}-\mathrm{NaCl}$ until no further protein was eluted; then the remaining protein was eluted by using $2 \mathrm{~mm}$-sodium phosphate buffer containing $0.25 \mathrm{M}-\mathrm{NaCl}$ (to elute protein I) or $0.5 \mathrm{M}-\mathrm{NaCl}$ (to elute the mixture of proteins I, II and apoprotein E).

* To whom correspondence and reprint requests should be addressed. 


\section{Lipoprotein lipase assay}

The lipoprotein lipase assay medium $(0.15 \mathrm{ml})$ contained $\left[{ }^{14} \mathrm{C}\right]$ palmitic acid-labelled intact or apoprotein-free chylomicrons ( $3 \mathrm{mg}$ of triacylglycerols), $3 \%$ (w/v) bovine serum albumin (Sigma Chemical Co., St. Louis, MO, U.S.A.) and $0.1 \mathrm{M}$-Tris $/ \mathrm{HCl}$ buffer, $\mathrm{pH} \mathrm{8.1.} \mathrm{Where}$ indicated, trypsin-treated chylomicrons were incubated with apoproteins for $20 \mathrm{~min}$ at room temperature before being mixed with the other assay components. The enzyme reaction was started by adding $0.1 \mathrm{ml}$ of rat heart lipoprotein lipase and incubation was carried out at $37^{\circ} \mathrm{C}$ for $20 \mathrm{~min}$ in a shaking water bath. The ${ }^{14} \mathrm{C}$-labelled non-esterified fatty acids released into the assay medium were extracted by the method of Belfrage \& Vaughan (1969)and their radioactivity measured.In all experiments, the amount of substrate was not limiting during the period of incubation. To obtain lipoprotein lipase, rat hearts were perfused with Krebs-Ringer bicarbonate buffer, as previously described (Lukens \& Borensztajn, 1978), to remove all contaminating plasma, followed by a $30 \mathrm{~s}$ perfusion with the same buffer containing 1 U.S.P. (U.S. Pharmacopeia) unit of heparin/ml (Upjohn, Kalamazoo, MI, U.S.A.) to release lipoprotein lipase from the organ. The released enzyme was used immediately after collection.

\section{Proteolysis of chylomicrons}

Chylomicrons were stripped of their apoproteins by enzymic hydrolysis with trypsin, as previously described (Borensztajn \& Kotlar, 1984).

\section{Clearance of chylomicrons}

Male Sprague-Dawley rats (200-220 g) were used in the experiments. They were lightly anaesthetized with diethyl ether and injected through a tail vein with $1 \mathrm{ml}$ of a mixture $\left(230 \mu \mathrm{g}\right.$ of cholesterol) of $\left[{ }^{3} \mathrm{H}\right]$ cholesterollabelled heparin-binding chylomicrons and $\left[{ }^{14} \mathrm{C}\right]$ cholesterol-labelled non-binding chylomicrons. At specified time intervals the animals were exsanguinated through the abdominal aorta, the blood allowed to clot and aliquots of the serum taken for radioactivity measurement. The total plasma volume of the animals determined by injection of ${ }^{125}$ I-labelled human serum albumin was $6.4 \pm 0.45 \mathrm{ml}$ (mean \pm S.D., $n=4$ ). To measure the incorporation of radioactivity in the livers, after exsanguination the livers were perfused through the portal vein with Krebs-Ringer bicarbonate buffer, pH 7.4, at $37^{\circ} \mathrm{C}$ for $1 \mathrm{~min}$ to remove particles that might have been trapped in the sinusoidal spaces. Liver samples were extracted with chloroform/methanol $(2: 1, \mathrm{v} / \mathrm{v})$ for the determination of radioactivity as previously described (Borensztajn et al., 1980).

\section{Other procedures}

Analytical electrophoresis of the apoproteins was carried out on SDS $/ 7.5 \%$-(w/v)-polyacrylamide disc gels as previously described (Borensztajn et al., 1985). Triacylglycerol and cholesterol were measured as described by Fletcher (1968) and Abel et al. (1951) respectively. Human $\beta_{2}$-glycoprotein I was obtained from Calbiochem-Behring (San Diego, CA, U.S.A.). Statistical significance of the difference between means was analysed by Student's $t$ test.

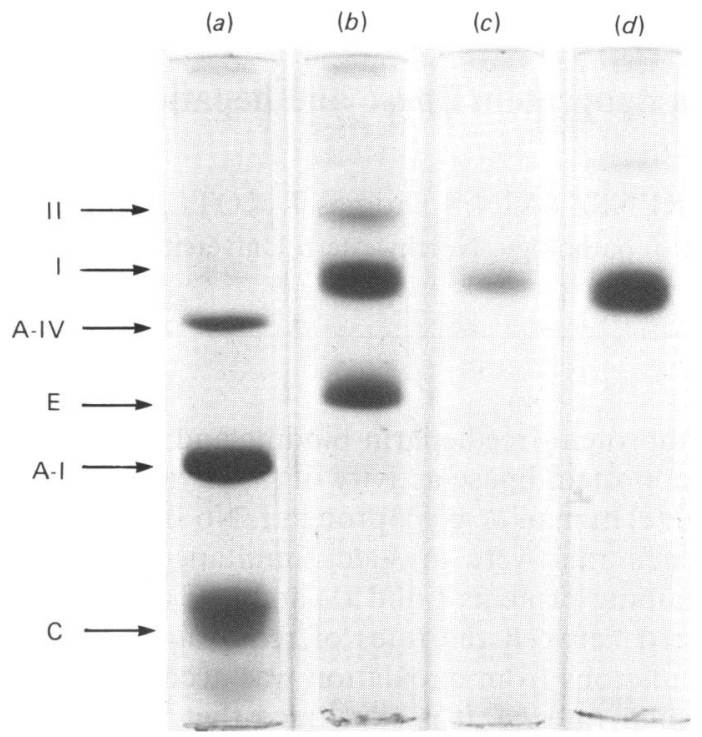

Fig. 1. Apoprotein patterns on polyacrylamide gels

(a) Non-binding apoproteins; (b) heparin-binding apoproteins; (c) protein I; (d) $\beta_{2}$-glycoprotein I. Protein I and chylomicron heparin-binding and non-binding apoproteins were obtained as described in the Materials and methods section. $\beta_{2}$-Glycoprotein I was from a commercial source (Calbiochem-Behring).

\section{RESULTS}

\section{Effect of apoproteins on lipoprotein lipase activity}

In Fig. 1 are shown the electrophoretic-gel patterns of the apoprotein preparations used. Chylomicron apoprotein mixtures separated by heparin-Sepharose chromatography into non-binding and heparin-binding groups are shown in gels $(a)$ and $(b)$ respectively. Protein I purified from rat lymph chylomicrons and $\beta_{2}$-glycoprotein I obtained from human plasma are shown in gels $(c)$ and (d) respectively.

In order to investigate the potential activating effects of the apoproteins on lipoprotein lipase, we used as substrate apoprotein-free chylomicrons as previously described (Lukens \& Borensztajn, 1978). This procedure involves, as a first step, the complete removal of apoproteins from the surface of the particles by proteolytic digestion. The resulting apoprotein-free, but otherwise intact, chylomicrons are a very poor substrate for lipoprotein lipase. In a second step, apoproteins are added to the proteinase-treated chylomicrons and their effects in restoring the capacity of the particles to act as substrate for lipoprotein lipase can then be readily evaluated.

Fig. 2 shows the results of experiments in which apoproteins were added to trypsin-treated chylomicrons, both heparin-binding and non-binding. In the absence of surface apoproteins the hydrolysis of both preparations of trypsin-treated chylomicrons was only about $10 \%$ of that of control chylomicrons $(100 \%)$. In preliminary experiments (results not shown) we established that the hydrolysis rate of triacylglycerols was the same for heparin-binding and non-binding chylomicrons. Addition of the apoprotein mixture containing $\mathrm{C}$ apoproteins (gel $a$, Fig. 1) completely restored the capacity of the 


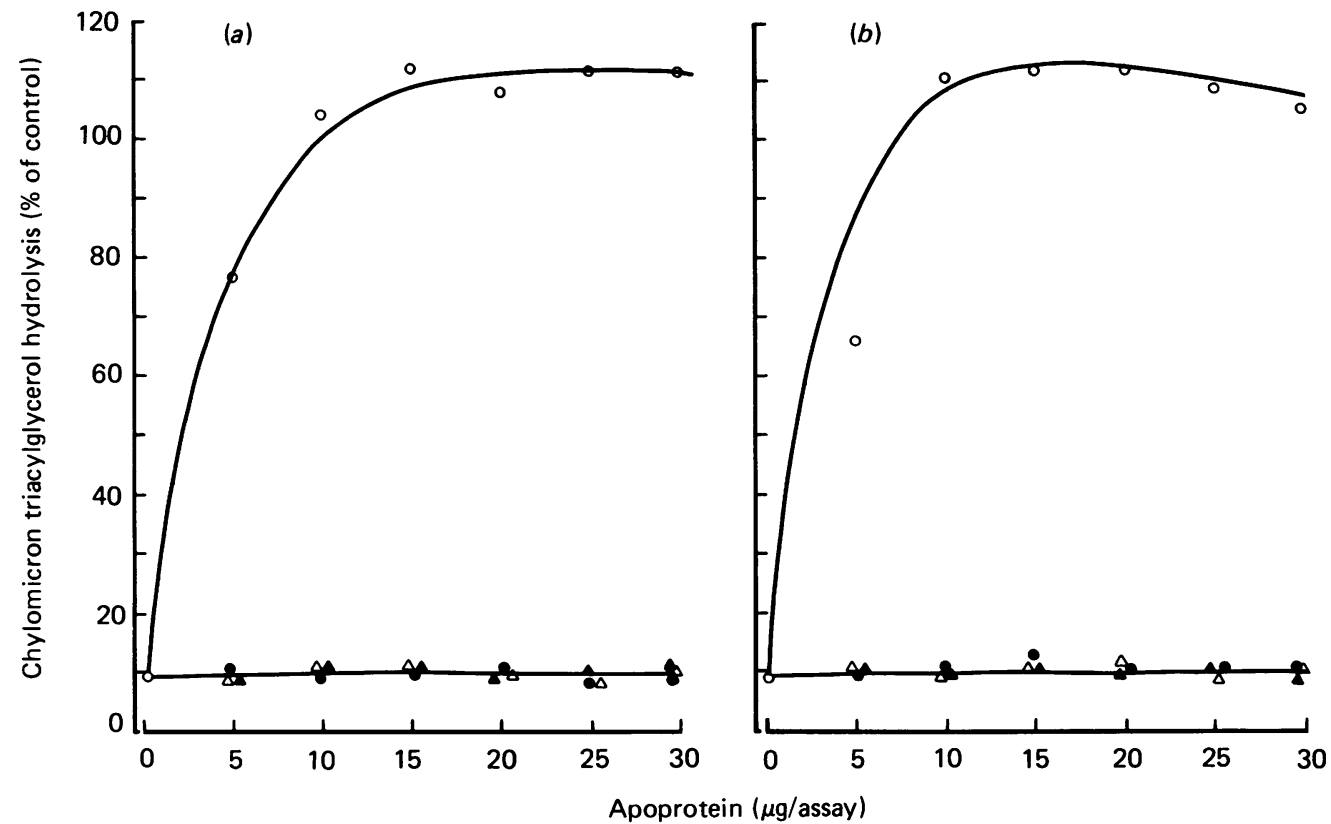

Fig. 2. Effect of apoproteins on the hydrolysis of triacylglycerols of apoprotein-free non-binding (a) and heparin-binding (b) chylomicrons

Chylomicrons that had been stripped of their apoproteins by proteolysis were incubated with increasing amounts of apoproteins before being used as substrate for lipoprotein lipase. Results are expressed as percentage hydrolysis of control chylomicrons $(100 \%)$, and each point represents the average result of assays carried out in duplicate. $\mathrm{O}$, Non-binding apoproteins (A-I, A-IV and $\mathrm{C}$ );, , heparin-binding apoproteins (I, II and E); $\triangle$, protein I; $\Delta, \beta_{2}$-glycoprotein I.

Table 1. Removal from circulation and hepatic uptake of heparin-binding and non-binding chylomicrons

Groups of four rats were injected simultaneously with a mixture $(230 \mu \mathrm{g}$ of cholesterol $)$ of $\left[{ }^{3} \mathrm{H}\right] \mathrm{cholesterol-labelled} \mathrm{heparin-binding}$ and $\left[{ }^{14} \mathrm{C}\right]$ cholesterol-labelled non-binding chylomicrons. After the times indicated the animals were exsanguinated for measurement of the total and cholesterol ester radioactivity in the serum. The livers were perfused for 1 min with Krebs-Ringer bicarbonate buffer, as described in the Materials and methods section, weighed and two separate samples taken for the measurement of radioactivity in their lipid extracts, as described in the Materials and methods section. Results are expressed as means \pm S.D.

\begin{tabular}{|c|c|c|c|c|c|c|}
\hline \multirow[b]{4}{*}{ Time $(\min )$} & \multicolumn{6}{|c|}{ Proportion of injected cholesterol radioactivity $(\%)$} \\
\hline & \multicolumn{4}{|c|}{ Serum } & \multirow{2}{*}{\multicolumn{2}{|c|}{$\begin{array}{l}\text { Liver } \\
\text { Total }\end{array}$}} \\
\hline & \multicolumn{2}{|c|}{ Total } & \multicolumn{2}{|c|}{ Ester } & & \\
\hline & ${ }^{3} \mathrm{H}$ & ${ }^{14} \mathrm{C}$ & ${ }^{3} \mathrm{H}$ & ${ }^{14} \mathrm{C}$ & ${ }^{3} \mathrm{H}$ & ${ }^{14} \mathrm{C}$ \\
\hline 2 & $71.3 \pm 5$ & $73.5 \pm 2.6$ & $70.6 \pm 13.7$ & $80.3+8.8$ & $8.1+1.0$ & $4.8+0.8$ \\
\hline 10 & $39.9 \pm 8.5$ & $42.7 \pm 8.2$ & $45.2 \pm 15.6$ & $47.9 \pm 11.8$ & $35.5 \pm 6.8$ & $29.2 \pm 6.7$ \\
\hline 20 & $11.5 \pm 2.7$ & $11.1 \pm 2.0$ & $9.8 \pm 1.3$ & $10.9 \pm 1.9$ & $76.4 \pm 2.5$ & $71.0 \pm 2.9$ \\
\hline 30 & $3.5 \pm 2.4$ & $3.9 \pm 2.4$ & $3.1 \pm 1.5$ & $3.4 \pm 2.6$ & $87.7 \pm 3.5$ & $81.2 \pm 2.8$ \\
\hline
\end{tabular}

trypsin-treated chylomicrons (both heparin-binding and non-binding) to be hydrolysed by lipoprotein lipase. Maximal activation was achieved by the addition to the assay system of $10 \mu \mathrm{g}$ of the combined apoproteins A-I, A-IV and C, of which only a small fraction was apoprotein C-II, the lipoprotein lipase activator. In contrast with these findings, no activation was observed when up to $30 \mu \mathrm{g}$ of protein I (gel $c$, Fig. 1), $\beta_{2}$-glycoprotein I (gel $d$, Fig. 1) or the mixture of heparin-binding proteins I, II and apoprotein $\mathrm{E}$ (gel $b$, Fig. 1) were added to the chylomicron preparations.

Removal from circulation of heparin-binding and nonbinding chylomicrons

We consider the possibility that heparin-binding and non-binding chylomicrons might be removed from circulation at different rates. To examine this possibility, we measured the simultaneous clearance from circulation of chylomicrons with or without associated proteins I and II. Chylomicrons were labelled with either $\left[{ }^{14} \mathrm{C}\right]$ cholesterol or $\left[{ }^{3} \mathrm{H}\right]$ cholesterol and the same amount of each preparation $(800 \mathrm{mg}$ of triacylglycerols) applied separately to heparin-Sepharose columns. All the heparin-binding fraction of the ${ }^{3} \mathrm{H}$-labelled chylomicrons was combined with all the non-binding fraction of the ${ }^{14} \mathrm{C}$-labelled chylomicrons. This resulted in a mixture in which the heparin-binding and non-binding fractions were in their original proportions. Portions of this double-labelled mixture were injected into rats, and at different time intervals groups of animals were killed and 
the total radioactivity as well as the cholesteryl ester radioactivity remaining in the plasma was measured. As the rat lacks cholesteryl ester transfer protein (Barter \& Lally, 1978), there is no exchange of cholesteryl ester between lipoproteins. Thus cholesteryl esters serve as reliable markers for the fate of chylomicrons. As shown in Table 1, no significant differences were detected in the removal from circulation of either the cholesteryl ester fraction or the total label.

\section{Hepatic uptake of remnants of heparin-binding and non-binding chylomicrons}

To verify that the disappearance of ${ }^{3} \mathrm{H}$ and ${ }^{14} \mathrm{C}$ label from circulation was due to the formation and clearance of chylomicron remnants, we measured the hepatic incorporation of the injected radioactivity. The results in Table 1 show that the disappearence of the ${ }^{3} \mathrm{H}$ - and ${ }^{14} \mathrm{C}$-labelled chylomicrons from circulation was, in fact, accompanied by a corresponding increase in the incorporation of both labels into the livers. These results demonstrate further that, except for the 2 min interval, remnants produced by the action of lipoprotein lipase on heparin-binding and non-binding chylomicrons were taken up by the livers at the same rate.

\section{DISCUSSION}

It has often been proposed (see Quinn et al., 1982) that the activating effect of apoprotein C-II on the catalytic action of lipoprotein lipase in vivo may be modulated by other apoproteins normally present on the surface of the triacylglycerol-rich lipoproteins. These proposals have been made on the basis of observations showing that the hydrolytic action of lipoprotein lipase on triacylglycerol emulsions can be either activated or inhibited by the addition of various apoproteins to the assay system. The physiological implications of these observations are not clear, however, since artificial substrates, rather than triacylglycerol-rich lipoproteins, were used in the enzyme assays, and rather large amounts of apoproteins were required to affect the enzyme activity. In the present study we used a previously reported system (Lukens \& Borenztajn, 1978) whereby chylomicrons stripped of their own surface apoproteins are employed to investigate the effects of apoproteins on the catalytic action of heart lipoprotein lipase. The results obtained confirmed our previous observations that apoprotein-free chylomicrons are poor substrates for lipoprotein lipase and that their capacity to be hydrolysed by this enzyme can be readily restored by the addition of apoprotein C-II to the assay system (Fig. 2). Identical activating effects of apoprotein C-II were observed when either heparin-binding or non-binding chylomicrons were used as substrate. We could not detect any activating effect of human $\beta_{2}$-glycoprotein I on heart lipoprotein lipase, even when large amounts of the protein (relative to the amounts of apoprotein C-II required to activate the enzyme) were added to the assay (Fig. 2). We further showed that protein I, which is normally associated with heparinbinding rat lymph chylomicrons and appears to be identical with $\beta_{2}$-glycoprotein I (Borensztajn et al., 1985), had no effect on the hydrolysis by lipoprotein lipase of either heparin-binding or non-binding chylomicron triacylglycerols. Thus the present results do not support the suggestion by Nakaya et al. (1980) that $\beta_{2}$-glycoprotein I (called 'apoprotein $\mathrm{H}$ ' by those authors) may play an important role in regulating lipoprotein lipase activity. This conclusion is reinforced by the results of the experiments carried out in vivo (Table 1), which showed that the rate of clearance from circulation of intact chylomicrons containing protein I was not different from that of chylomicrons that did not have this apoprotein. Apoprotein $E$ has also been suggested to exert an activating effect on lipoprotein lipase (Quarfordt et al., 1977; Yamada \& Murase, 1980). The present results, showing that the apoprotein E-containing mixture of heparin-binding proteins failed to activate the enzyme (Fig. 2) do not support this proposition.

In the process of being degraded by lipoprotein lipase chylomicrons lose some of their surface apoproteins (Mjos et al., 1975; Tall et al., 1979). We do not yet know whether proteins I and II are also lost from the surface of the particles or whether, like apoproteins E and B, they remain associated with the remnants formed. If the latter occurs, then the results in Table 1 would indicate that these proteins do not have an effect on the hepatic uptake of remnants. In conclusion, the present results, showing that heparin-binding and non-binding chylomicrons share the same metabolic fate, indicate that proteins I and II are not involved in the catabolism of these lipoporteins. The metabolic functions of proteins I and II remain to be determined.

This work was supported by the United States Public Health Research Grant HL 30192 and by the Bess Eisenberg Memorial Fund.

\section{REFERENCES}

Abel, L. I., Levy, B. B., Brodie, B. B. \& Kendall, F. E. (1951) J. Biol. Chem. 195, 357-366

Barter, P. J. \& Lally, J. I. (1978) Biochim. Biophys. Acta 531, 233-236

Belfrage, P. \& Vaughan, M. (1969) J. Lipid Res. 10, 341-344

Bollman, J. L., Cain, J. C. \& Grindley, J. H. (1948) J. Lab. Clin. Med. 33, 1349-1352

Borensztajn, J. \& Kotlar, T. J. (1984) Proc. Natl. Acad. Sci. U.S.A. 81, 5863-5866

Borensztajn, J., Kotlar, T. J. \& McNeill, B. J. (1980) Biochem. J. 192, 845-851

Borensztajn, J., Kotlar, T. J. \& Meredith, S. C. (1985) J. Biol. Chem. 260, 13047-13052

Fletcher, M. J. (1968) Clin. Chim. Acta 22, 393-397

Lukens, T. W. \& Borensztajn, J. (1978) Biochem. J. 175, 53-61

Mjos, O. D., Faergeman, O., Hamilton, R. L. \& Havel, R. J. (1975) J. Clin. Invest. 56, 603-615

Nakaya, Y., Schaefer, E. J. \& Brewer, H. B., Jr. (1980) Biochem. Biophys. Res. Commun. 95, 1168-1172

Polz, E. \& Kostner, G. M. (1979) FEBS Lett. 102, 183-186

Polz, E., Wurm, H. \& Kostner, G. M. (1980) Int. J. Biochem. 11, 265-270

Quinn, D., Shirai, K. \& Jackson, R. L. (1982) Prog. Lipid Res. 22, 35-38

Quarfordt, S. H., Hilderman, H., Greenfield, M. R. \& Shelburne, F. A. (1977) Biochem. Biophys. Res. Commun. 78, 302-308

Tall, A. R., Green, P. H. R., Glickman, R. M. \& Riley, J. W. (1979) J. Clin. Invest. 64, 977-989

Yamada, N. \& Murase, T. (1980) Biochem. Biophys. Res. Commun. 94, 710-715 